\title{
Betulinic Acid in Complex with a Gamma-Cyclodextrin Derivative Decreases Proliferation and in Vivo Tumor Development of Non-Metastatic and Metastatic B164A5 Cells
}

Codruta Soica ${ }^{1}$, Corina Danciu ${ }^{1, *}$, Germaine Savoiu-Balint ${ }^{1{ }^{*} *}$, Florin Borcan ${ }^{1}$, Rita Ambrus ${ }^{2}$, Istvan Zupko ${ }^{3}$, Florina Bojin ${ }^{4}$, Dorina Coricovac ${ }^{1}$, Sorina Ciurlea ${ }^{1}$, Stefana Avram ${ }^{1}$, Cristina Adriana Dehelean ${ }^{1}$, Teodora Olariu ${ }^{5}$ and Petru Matusz ${ }^{4}$

1 Faculty of Pharmacy, Victor Babeş University of Medicine and Pharmacy, 2 EftimieMurgu, 300041 Timisoara, Romania; E-Mails: codrutasoica@umft.ro (C.S.); fborcan@yahoo.com (F.B.); dorina_gheorgheosu@yahoo.com (D.C.); sorinaciurlea@yahoo.com (S.C.);

stefana.feflea@gmail.com (S.A.); cadehelean@umft.ro (C.A.D.)

2 Institute of Pharmaceutical Technology, University of Szeged, 6 Eotvos Ut., H-6720 Szeged, Hungary; E-Mail: rita-techno@freemail.hu

3 Department of Pharmacodynamics and Biopharmacy, University of Szeged, 6 Eotvos Str., H-6720 Szeged, Hungary; E-Mail: zupko@pharm.u-szeged.hu

4 Faculty of Medicine, Victor Babeş University of Medicine and Pharmacy, 2 EftimieMurgu, 300041 Timisoara, Romania; E-Mails: florinabojin@umft.ro (F.B.); matusz@umft.ro (P.M.)

5 Faculty of Medicine, Vasile Goldis University, 310045 Arad, Romania;

E-Mail: olariu.teodora@yahoo.com

* Authors to whom correspondence should be addressed;

E-Mails: corina.danciu@umft.ro (C.D.); savoiugema@umft.ro (G.S.-B.);

Tel.: +40-744-648855 (C.D.); Fax: +40-256-226134 (C.D.).

Received: 4 January 2014; in revised form: 8 April 2014 / Accepted: 10 April 2014 /

Published: 9 May 2014

\begin{abstract}
Betulinic acid, a very promising anti-melanoma agent, has very low water solubility that causes low bioavailability. To overcome this inconvenience, a highly water-soluble cyclodextrin was used (octakis-[6-deoxy-6-(2-sulfanyl ethanesulfonic acid)]$\gamma$-cyclodextrin). The complex was physico-chemically analyzed using differential scanning calorimetry (DSC), X-ray and scanning electron microscopy (SEM) methods and then in vitro tested for its antiproliferative activity by the MTT assay and by cell cycle analysis. Finally, the complex was tested in vivo using an animal model of murine melanoma developed in C57BL/6J mice, where it caused a reduction in tumor volume and weight.
\end{abstract}


The study revealed the beneficial influence of betulinic acid inclusion into the cyclodextrin in terms of antiproliferative activity and in vivo tumor development.

Keywords: betulinic acid; DSC; X-ray diffraction; SEM; MTT test; C57BL/6J mice

\section{Introduction}

Betulinic acid (BA, Figure 1) was discovered as an antimelanoma agent in 1995 by Pisha et al. [1]. Since then, it has been proven as an antitumor agent on many other cell lines: glioma, medulloblastoma, glioblastoma, ovarian carcinoma, lung carcinoma, cervical carcinoma, head and neck carcinoma, hematological malignancies, and skin carcinoma [2,3]. The most important advantage of BA as an anticancer agent is its selective activity on tumor cells with no cytotoxic activity on normal cells [4]. Based on these facts, BA has been introduced in the RAID (Rapid Access to Intervention Development) program by the United States NCI (National Cancer Institute) [5]. One important facet in anticancer treatment is finding a way to prevent or stop metastasis development. BA has been proven to act more aggressively on human metastatic C8161 melanoma cells than their non-metastatic equivalent (C8161/neo 6.3) [6]. Additionally, in combination with vincristine, BA was able to prevent metastasis to the lungs in a B16F10 melanoma model in mice [7].

All research regarding the anticancer activities of BA and other pentacyclic triterpenes is hampered by low water solubility, which greatly limits therapeutic applications as well as bioavailability $[2,8]$. To overcome this solubility issue, cyclodextrin (CD) complexation has been accomplished using $\beta$ - and $\gamma$-derivatives with high water solubility $[9,10] . \gamma$-Derivatives were described as the most appropriate host molecules for the bulky structure of BA (Figure 1) [11], and the complexes were physico-chemically characterized and in vitro/in vivo tested [9-12]. In spite of a significant increase in water solubility, which led to an optimized bioavailability, the stability constants of the final complexes were rather low [9-12]. Because of this result, an efficient targeted delivery of the active compound, essential in cancer therapy [13], could not be accomplished. Based on this information, semisynthetic $\gamma$-derivatives with hydrophobic substituents were introduced as host molecules and evaluated using NMR techniques [14]. An even better water solubility was achieved and, more importantly, a very strong complex was formed [14], capable of retaining the active substance long enough to reach its final delivery site.

Figure 1. Betulinic acid (BA) molecular structure.

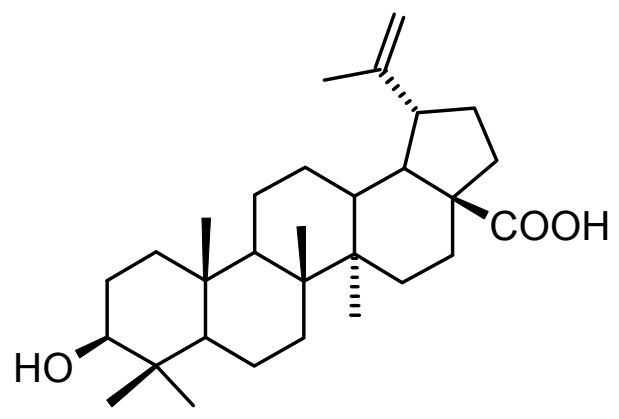


The present paper aims to present a comprehensive physico-chemical and biological characterization of BA complexed with octakis-[6-deoxy-6-(2-sulfanyl ethanesulfonic acid)]- $\gamma$-CD (GCDG) using in vitro tests on tumor cell lines and in vivo tests on experimental animal models.

\section{Results and Discussion}

\subsection{Scanning Electron Microscopy (SEM)}

Scanning electron microscopy (SEM) is successfully used in the evaluation of the microscopic aspects of the active compound, complexing cyclodextrin and complex formation (Figure $2 \mathrm{a}-\mathrm{c}$ ).

Figure 2. Scanning electron microscopy (SEM) pictures of (a) Betulinic acid (BA); (b) octakis-[6-deoxy-6-(2-sulfanyl ethanesulfonic acid)]- $\gamma$-cyclodextrin (GCDG); and (c) BA:GCDG, 1:1 complex.

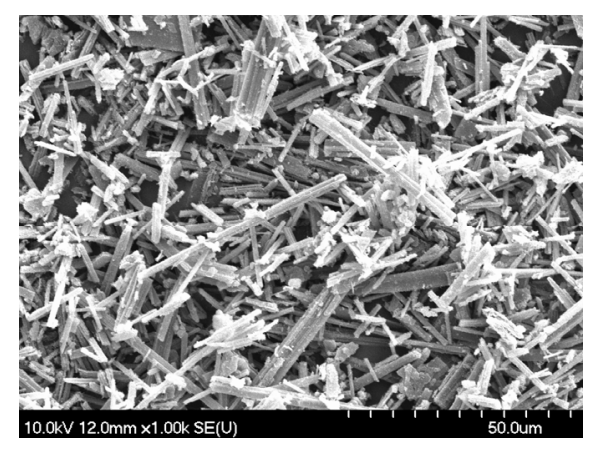

(a)

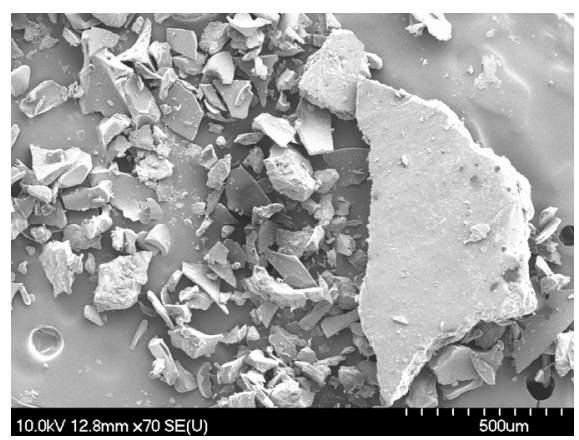

(b)

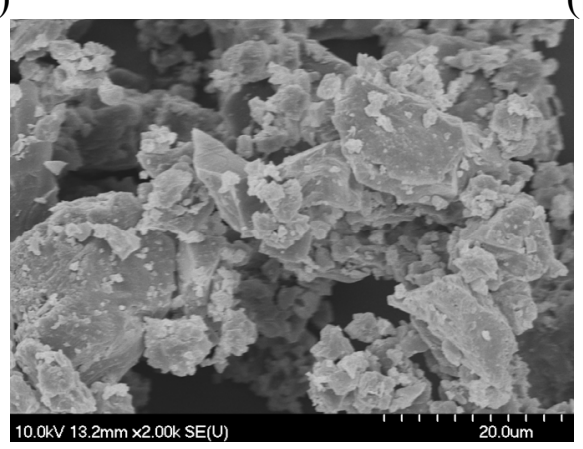

(c)

Although SEM is not a decisive method in terms of absolutely confirming complex formation, the method helps assess the presence of only one component in the final products. In Figure 2a, BA exhibits crystalline particles characterized by regular parallelepiped shape and similar size. The cyclodextrin (Figure 2b) shows amorphous particles of irregular shape and size, and some of them are highly aggregated. The physical mixture of BA and GCDG (not shown) contains both crystalline and amorphous particles adhering to mutual surfaces. A dramatic change in morphology and crystallinity degree is noticed in the 1:1 kneaded complex (Figure 2c), revealing a presumable interaction in the solid state. SEM pictures of the final product exhibit small particles with a clear tendency to aggregate, a specific behavior for amorphous particles of a single component, therefore leading to the conclusion that real complexing took place. 


\subsection{Differential Scanning Calorimetry (DSC)}

Differential scanning calorimetry (DSC) analysis was performed in a temperature range of $0-350{ }^{\circ} \mathrm{C}$ (Figure 3).Within this range, BA revealed a very small exothermic peak at approximately $60{ }^{\circ} \mathrm{C}$ and a strong endothermic peak at approximately $306^{\circ} \mathrm{C}$, corresponding to the decomposition of the substance.

Figure 3. Differential scanning calorimetry (DSC) curves of BA, octakis-[6-deoxy-6(2-sulfanyl ethanesulfonic acid)]- $\gamma$-cyclodextrin (GCDG) and their 1:1 complex. As carrier gas argon was used, the heating rate was maintained at $5{ }^{\circ} \mathrm{C} / \mathrm{min}$, while the sample weight was $2-5 \mathrm{mg}$. Experiments were conducted from 25 up to $300^{\circ} \mathrm{C}$.

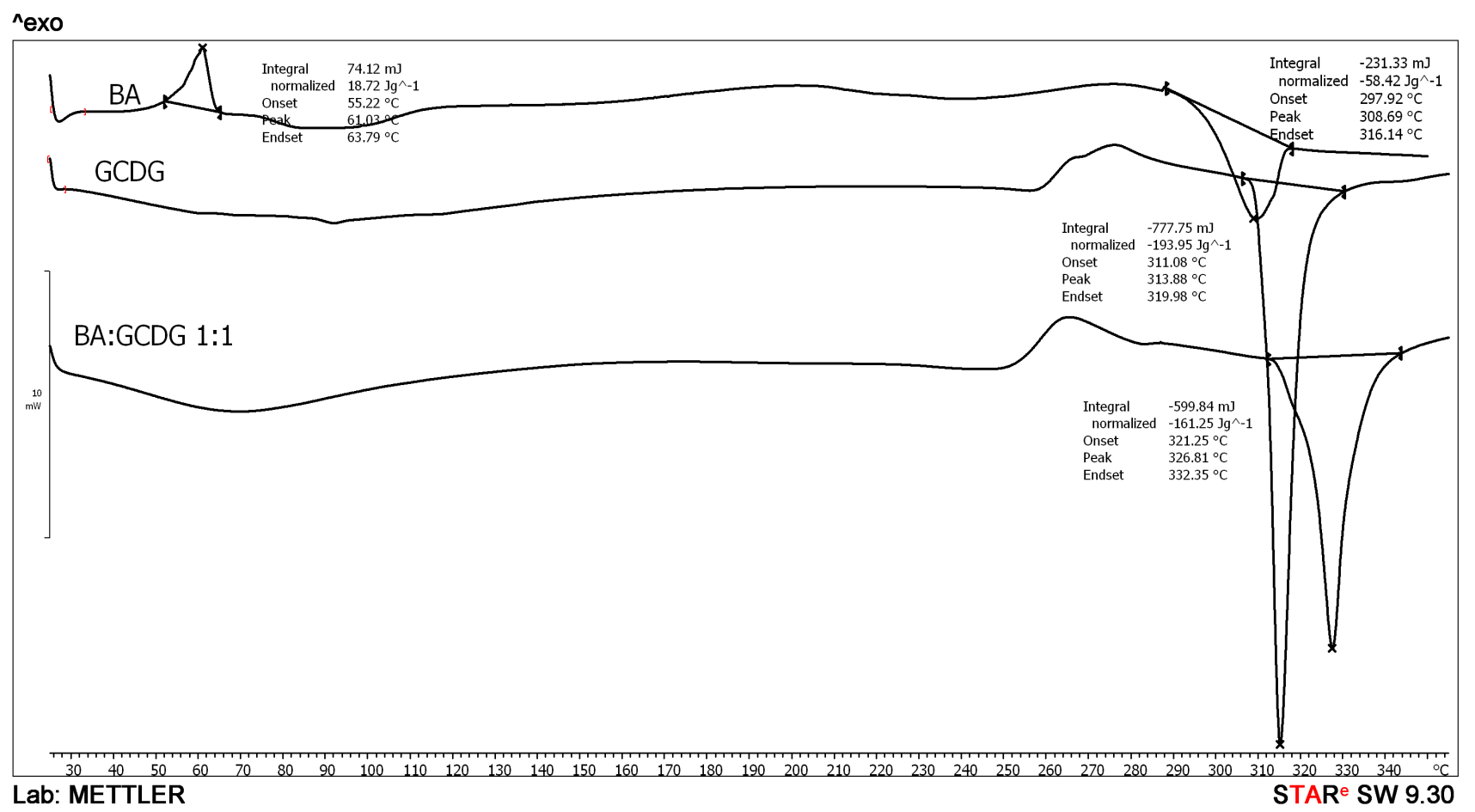

The cyclodextrin also presented a very sharp endothermic peak at approximately $313{ }^{\circ} \mathrm{C}$, indicating a strong endothermic process accompanying its decomposition. In the physical mixture (not presented), the DSC curve is practically the sum of the individual curves of both compounds. In contrast, for the 1:1 kneaded product, the DSC curve exhibits a very smooth endothermic process before $100{ }^{\circ} \mathrm{C}$, as determined by water evaporation; moreover, the complete disappearance of both BA peaks and the presence of the cyclodextrin peak are observed, with a shift of position from $313-326^{\circ} \mathrm{C}$. This new peak, presumably attributed to the complex decomposition, indicates the interaction that took place between the two components with the formation of the 1:1 complex. The disappearance of the BA peaks proves that the active compound is completely included in the cyclodextrin cavity and is unable to perform as the pure drug. 


\subsection{X-ray Analysis}

$\mathrm{X}$-ray analysis is typically used in the study of cyclodextrin complexing to characterize the changes that appear in the crystalline state of a compound as a result of intermolecular interaction. The X-ray diagrams of BA and GCDG are compared to the X-ray profile of the complex, revealing significant changes (Figure 4).

Figure 4. X-ray diffractograms of BA, GCDG and BA:GCDG 1:1. The measurements were conducted with a $50 \mathrm{kV}$ tube voltage and tube current of $40 \mathrm{~mA}$ in step scan mode (step size 0.035 , counting time $1 \mathrm{~s}$ per step).

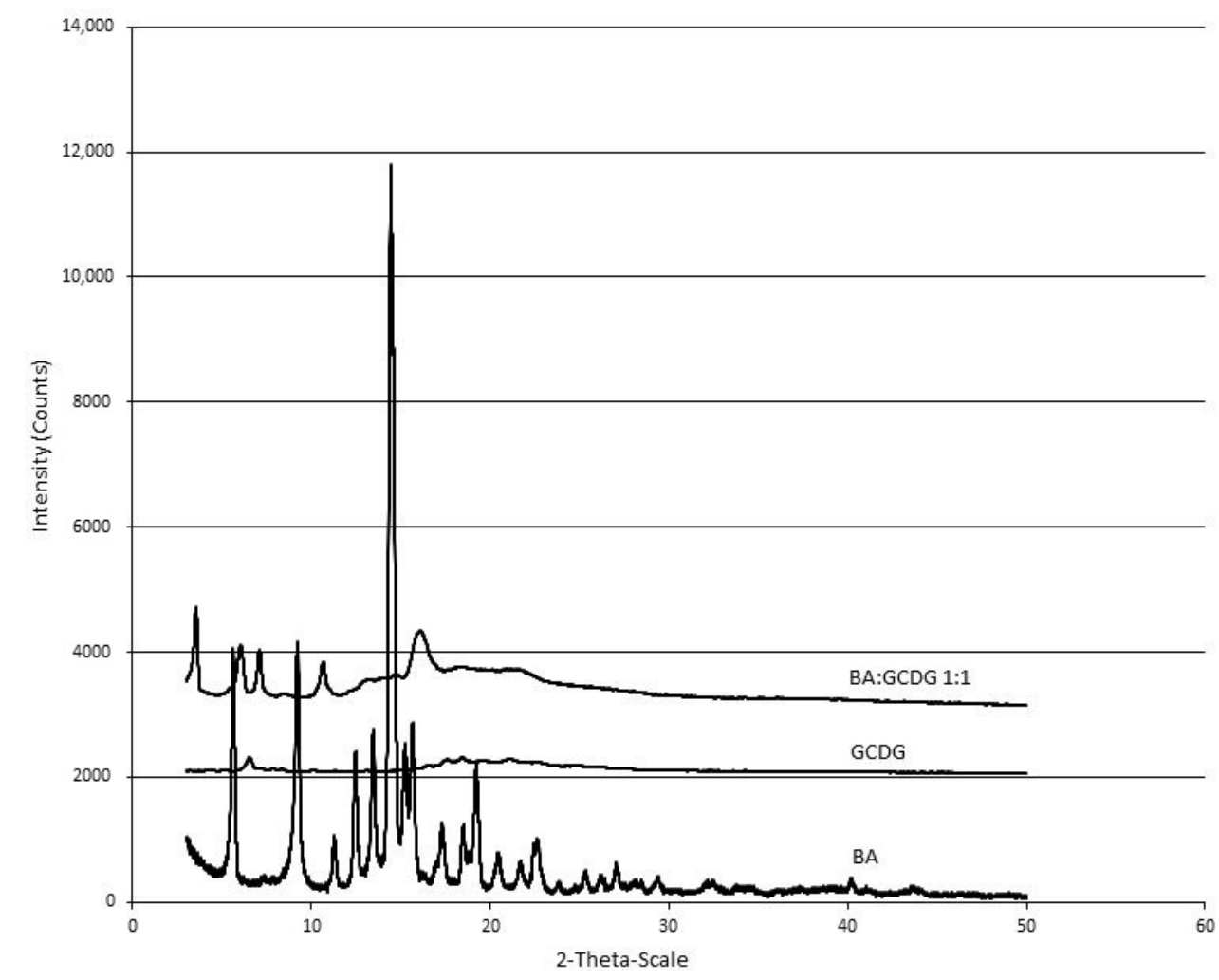

The BA X-ray diagram exhibits sharp peaks, which usually characterize crystalline compounds [15]. The cyclodextrin involved in the experiment reveals an almost flat X-ray diagram, with no distinguishable peaks, a profile that characterizes its amorphous nature. The diffractogram of the physical mixture of BA and GCDG (not shown) practically represents the sum of the individual diffractograms, revealing the BA peaks at a lower intensity compared with the pure compound in direct proportionality with its concentration in the mixture. The 1:1 complex provided a completely different X-ray diffractogram, in which several new peaks indicate the presence of a crystalline phase. Interestingly, the position of the new peaks differs substantially compared to the pure substance or its physical mixture with the cyclodextrin. The appearance of new peaks of different intensity and position can be considered evidence of real inclusion complex formation. Given the inclusion of BA inside of the GCDG cavity, BA-related peaks have disappeared, and a new compound emerged, characterized by a completely new X-ray profile. 


\subsection{MTT Assay}

The MTT proliferation assay indicated that BA inhibited the growth of both non-metastatic and metastatic B164A5 cells (Figure 5a,b). A slightly increased inhibitory activity on metastatic cells compared to the non-metastatic murine cell line was observed (57.89\% viable cells $v$ s. $61.82 \%$ viable cells, after $72 \mathrm{~h}$ of incubation). BA complexing with the newly synthesized cyclodextrin GCDG led to an improved antiproliferative activity, but the increase was not statistically relevant. After $72 \mathrm{~h}$ of incubation with the BA:GCDG complex, $50.30 \%$ of the B164A5 cells were viable, whereas only $42.33 \%$ of the metastatic B164A5 cells were viable under the same conditions. GCDG alone did not produce any significant effect on the non-metastatic or metastatic B164A5 cell proliferation. Our research group has previously reported on the antiproliferative effect of another triterpene with similar structure, betulin, on A431 (skin epidermoid carcinoma), A2780 (ovarian carcinoma), HeLa (cervical adenocarcinoma) and MCF7 (breast adenocarcinoma) [16] cell lines. Additionally, betulin, which differs from BA by a single functional group, was also described for its property to induce an antiproliferative effect on other human cell lines, such as hepatoma (HepG2) cells and lung adenocarcinoma (A549) cells [17]. Anticancer effects were also reported for neuroblastoma (SK-N-AS) cells and colon carcinoma (HT-29) cells [18]. However, as reported so far in several significant papers, BA remains the triterpene of choice for anticancer activity on both human and murine melanoma models. $[1,19,20]$. The conversion of betulin to BA follows a rather easy oxidative process [21]. The above mentioned results led us to the conclusion that in terms of antiproliferative effects, triterpene complexing with the newly synthesized $\mathrm{CD}$ is an interesting option to increase the antiproliferative activity. Increased anticancer activity for hydrophobic compounds after the incorporation in different types of CDs was previously reported in the literature [22-24]. Furthermore, by comparing the antiproliferative activity of BA on non-metastatic and metastatic B164A5 cells, we observed an increased sensitivity of the metastatic B164A5 cells compared to non-metastatic cells demonstrated by the percentage of viable cells, but the results were not statistically significant $(p=0.93)$.

Figure 5. MTT assay showing the percentage of viable cells after $72 \mathrm{~h}$ of incubation with $10 \mathrm{mM}$ BA and BA:GCDG 1:1 for non-metastatic (a) and metastatic (b) B164A5 cells. ns means not significant statistically.

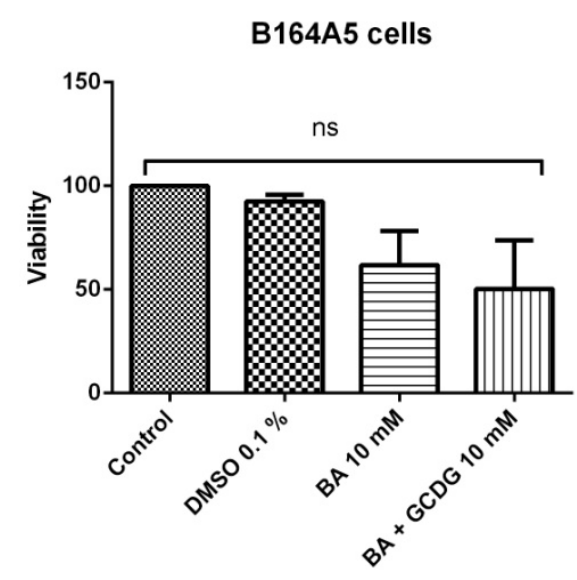

(a)

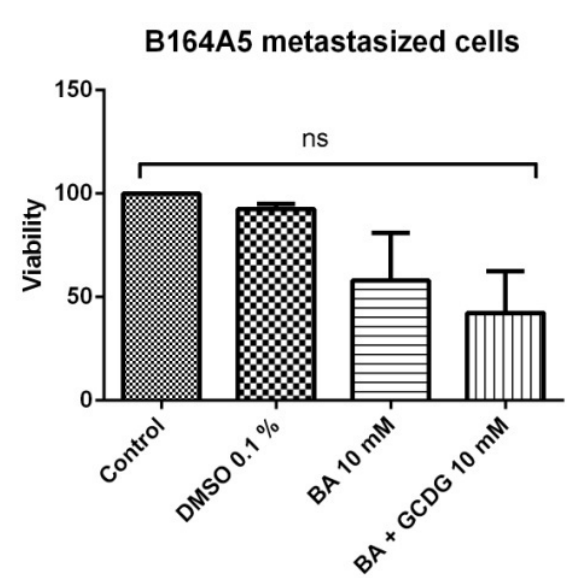

(b) 


\subsection{Cell Cycle}

The cell cycle analysis was conducted on both non-metastatic and metastatic B164A5 cells after incubation with BA and BA:GCDG 1:1 complex, respectively, and showed a G0/G1 arrest in both cases (Table 1). The capacity of BA to arrest the cell cycle in the G0/G1 phase was previously reported in the literature for various tumor cells lines, for example, Jurkat cells and cultured vascular smooth muscle cells [25-28]. BA cytotoxicity was noted to be selective on tumor cell lines but not on normal cells [4,29]. New semi-synthetic derivatives have been described to induce an $\mathrm{S}$ phase arrest for HepG2, HeLa and Jurkat cells [30]. By comparing the distribution in the phases of the cell cycle for non-metastatic and metastatic B164A5 cells after incubation with $10 \mathrm{mM}$ BA for $72 \mathrm{~h}$, we noticed that the percentage of cells blocked in the G0/G1 phase was increased in non-metastatic B164A5 cells as compared to the metastatic cells, having an average value of $15.55 \%$ cells blocked in the G0/G1 for non-metastatic B164A5 cells and 5.95\% for metastatic B164A5 cells. Our results also showed that the incorporation of BA in GCDG increased the antiproliferative activity of the natural compound, leading to a higher number of cells blocked in the G0/G1 phase compared to pure BA. We observed that $23.29 \%$ of non-metastatic B164A5 cells and $15.41 \%$ of metastatic B164A5 cells were blocked in the G0/G1 phase. GCDG alone did not produce any significant effect on the cell cycle phases of the non-metastatic and metastatic B164A5 cells.

\subsection{Annexin V-FITC-PI Double Staining Assay}

Annexin V-FITC-PI double staining is one of the most commonly employed assays to test the pro-apoptotic effects of active compounds [31]. BA has been previously reported to be a pro-apoptotic agent, causing late and early apoptosis on a wide range of cancer cell lines through the mitochondrial pathway [32,33]. Furthermore, BA cooperates with other anticancer drugs in inducing apoptosis [20]. Additionally, BA derivatives have been described for their pro-apoptotic activity on the B164A5 murine melanoma cell line [34]. The present study provides information concerning the activity of BA alone or incorporated in a hydrophilic CD, the newly synthesized GCDG, on non-metastatic and metastatic murine melanoma B164A5 cells. After $72 \mathrm{~h}$ of incubation of cells with $10 \mathrm{mM}$ BA, late apoptosis was the predominant phenomenon detected. Early apoptosis, but not late apoptosis, was significantly different between the non-metastatic (5.08\% early apoptotic cells; $74.47 \%$ late apoptotic cells) and metastatic cells (14.05\% early apoptotic cells; $76.94 \%$ late apoptotic cells) (Figures 6 and 7). Under our experimental conditions, contrary to the beneficial effects recorded for the antiproliferative effect, it seems that in the context of apoptosis, BA incorporation in GCDG is an inappropriate approach due to a drastic decrease in the number of early and late apoptotic cells compared to pure BA. Based on the fact that similar results were previously reported in the literature for uremic media on endothelial cells and for interferon $\gamma$ on murine astrocytes [35,36], we presume that the myc proto-oncogene family is involved in this behavior. Further investigation will be conducted to elucidate this outcome. GCDG alone did not produce any significant effect on the apoptosis of non-metastatic and metastatic B164A5 cells. The differences between the means were assessed using one way ANOVA followed by Bonferroni's post-test, and $p<0.05$ was considered statistically significant. Furthermore, to collect more data concerning the apoptotic events, we analyzed the 
expression of one initiator caspase, namely caspase 2. It is already known that the effector caspase 3 is stimulated after the incubation of B16 cells with BA [34]. Additionally, another pentacyclic triterpene, ursolic acid, was described to activate caspase 3 in another melanoma cell line, M4Beu [37]. Caspase 2 was not expressed by BA or BA:GCDG complex (Supplementary Information) treatment, suggesting that caspase 3 may be activated by another initiator caspase.

Table 1. Evaluation of cell cycle phases variation between control, B164A5 and B164A5 metastatic melanoma cells treated with GCDG, BA and their 1:1 complex.

\begin{tabular}{|c|c|c|c|c|c|c|c|c|}
\hline \multirow{3}{*}{$\begin{array}{l}\text { Sample } \\
(10 \mathrm{mM})\end{array}$} & \multicolumn{4}{|c|}{ Cell cycle phases for non-metastatic } & \multirow{2}{*}{\multicolumn{4}{|c|}{$\begin{array}{c}\text { Cell cycle phases for metastatic } \\
\text { B164A5 cells }\end{array}$}} \\
\hline & \multicolumn{4}{|c|}{ B164A5 cells } & & & & \\
\hline & $\begin{array}{c}\text { under-G0 } \\
(\%)\end{array}$ & G0/G1 (\%) & $\mathrm{S}(\%)$ & G2/M (\%) & $\begin{array}{c}\text { under-G0 } \\
(\%)\end{array}$ & G0/G1 (\%) & $\mathrm{S}(\%)$ & G2/M (\%) \\
\hline Control & $2.88 \pm 0.14$ & $64.32 \pm 2.13$ & $21.17 \pm 0.22$ & $11.63 \pm 0.17$ & $1.24 \pm 1.28$ & $71.68 \pm 3.14$ & $18.43 \pm 1.19$ & $8.65 \pm 1.21$ \\
\hline DMSO & $1.49 \pm 0.22$ & $69.43 \pm 1.39$ & $19.81 \pm 0.34$ & $9.27 \pm 0.31$ & $1.93 \pm 1.17$ & $68.39 \pm 2.67$ & $17.03 \pm 0.28$ & $12.65 \pm 1.19$ \\
\hline BA & $0.79 \pm 3.4$ & $87.61 \pm 1.64$ & $6.14 \pm 0.28$ & $5.46 \pm 0.25$ & $1.39 \pm 2.21$ & $87.09 \pm 3.03$ & $7.45 \pm 1.65$ & $4.07 \pm 3.42$ \\
\hline BA:GCDG & $2.29 \pm 1.27$ & $79.87 \pm 1.94$ & $11.98 \pm 1.73$ & $5.86 \pm 2.01$ & $2.97 \pm 2.27$ & $77.53 \pm 2.29$ & $8.29 \pm 3.02$ & $11.21 \pm 1.98$ \\
\hline
\end{tabular}

Figure 6. Representative dot-plots for Annexin V-FITC-PI-double staining after a period of incubation of $72 \mathrm{~h}$ for non-metastaticB164A5 cells: (a) Control; (b) BA $10 \mathrm{mM}$; (c) BA:GCDG $10 \mathrm{mM}$; and (d) quantification as percent viable cells during apoptosis (early and late apoptosis) and necrosis, using FACS software of the non-metastatic B164A5 cells: control, treated with BA dissolved in DMSO and BA:GCDG complex. Data are means $\pm \mathrm{SE}$ of at least three independent experiments.

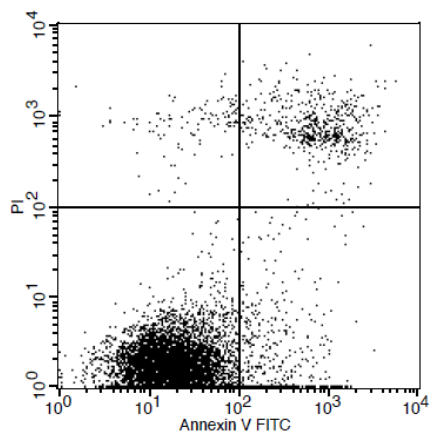

(a)

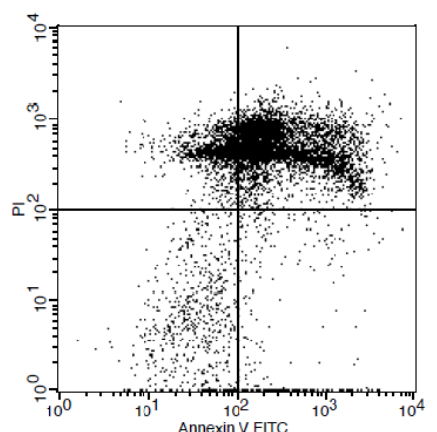

(b)

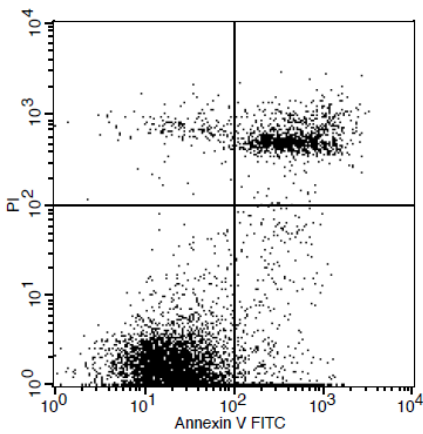

(c)

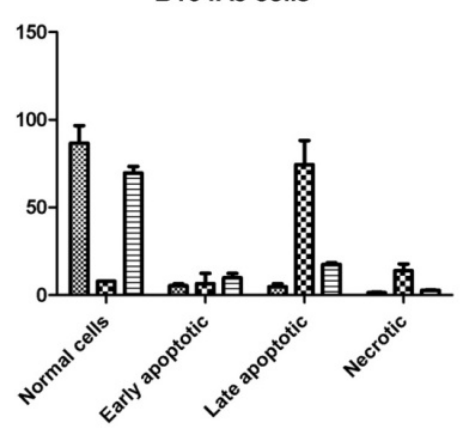

(d) 
Figure 7. Representative dot-plots for Annexin V-FITC-PI-double staining after a period of incubation of $72 \mathrm{~h}$ for metastatic B164A5 cells: (a) Control; (b) BA $10 \mathrm{mM}$; (c) BA:GCDG $10 \mathrm{mM}$; and (d) quantification as percent viable cells during apoptosis (early and late apoptosis) and necrosis, using FACS software of the metastatic B164A5 cells: control, treated with BA dissolved in DMSO and BA:GCDG complex. Data are the mean $\pm \mathrm{SE}$ of at least three independent experiments.

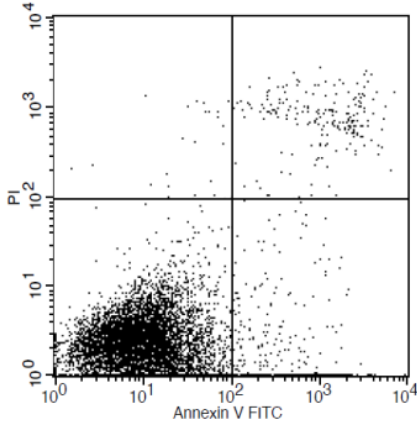

(a)

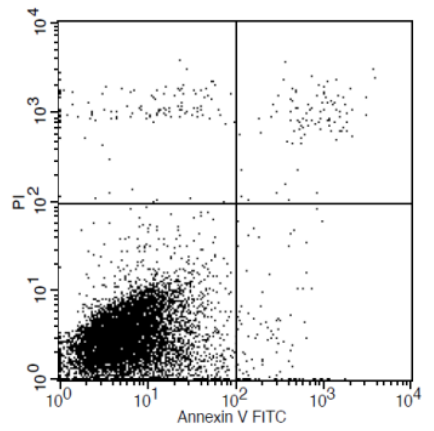

(b)

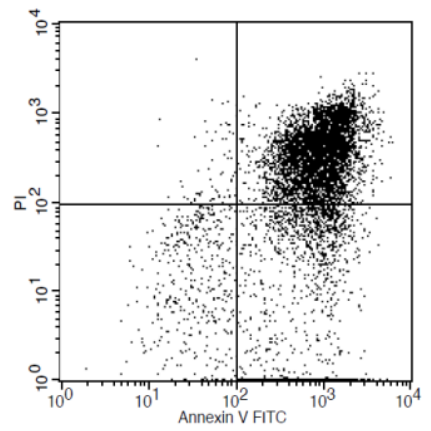

(c)

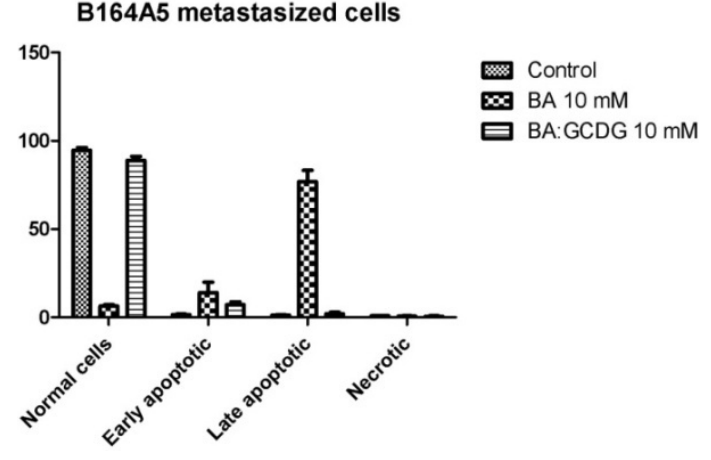

(d)

\subsection{In Vivo Experiments}

To evaluate the effects of the BA:GCDG complex in vivo, we developed several experiments, including macroscopic follow-up (measurements of tumor volume/day and tumor weight after the mice were sacrificed-Figure 8, (1),(2)), histopathological analysis of tumor using the haematoxylin-eosin (HE) method (Figure 9, (1),(2)) and measurements of distinct skin parameters (transepidermal water loss (TEWL), melanin and erythema-Figure 10a-c).

Melanoma parameters in the context of tumor volume and weight were visibly reduced, as observed in the macro images (Figure 8, (1a),(1b)). Histological evaluation confirmed the differences between the two groups; for group A (non-treated), a more intense pathological process was observed, with a highly proliferative aspect (Figure 9, (1a),(1b)), while in group B, the presence of melanoma at the skin level was detected with lower semi-quantitative expression compared to the first group (Figure 9, (2a),(2b)). 
Figure 8. (1) Macroscopic images of tumor development on day 21 of the experiment developed in C57BL/6J mice: (a) Non-treated group (control group); and (b) BA:GCDG complex-treated group. (2) Tumor development: (a) Tumor volume $\left(\mathrm{mm}^{3}\right)$; and (b) Tumor weight $(\mathrm{g})$ for the treated and non-treated groups. Tumor growth $(\mathrm{mm})$ was measured daily using a caliper, and tumor volume was estimated by using the following formula: length $\times$ width $^{2} / 2$. The administration of BA complex started on the first day after the murine melanoma cells were inoculated and was performed daily $(100 \mathrm{mg} / \mathrm{kg}$, intraperitoneally) until the final day of the experiment. Paired Student's $t$ tests or one-way ANOVA followed by Bonferroni's post-tests were used; $p<0.05(*), p<0.01(* *)$ and $p<0.001(* * *)$ are indicated.

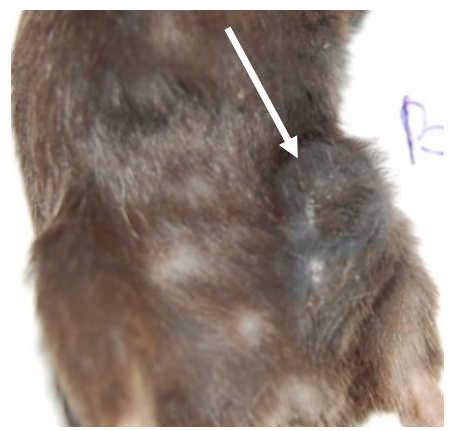

(1a)

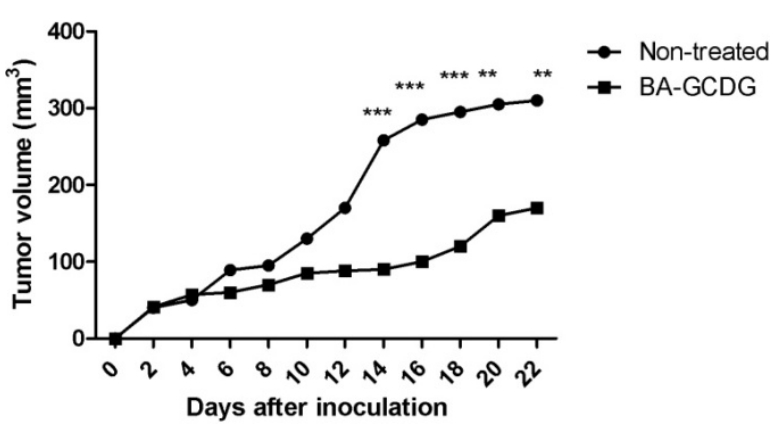

(2a)

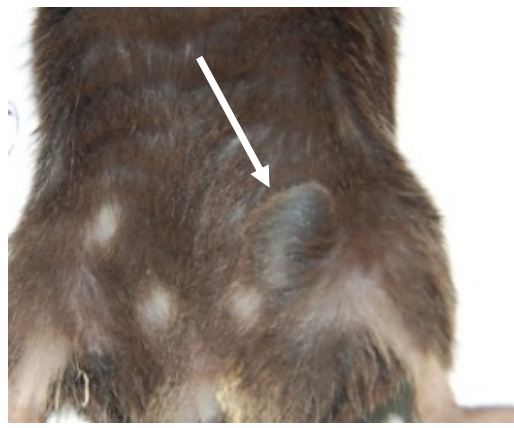

(1b)

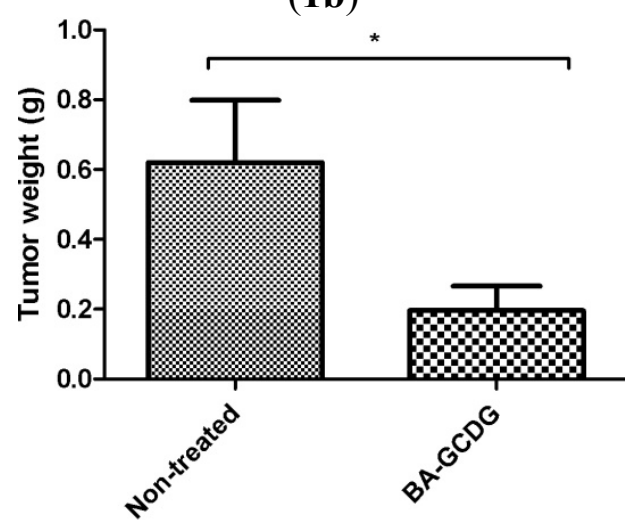

(2b)

Figure 9. Histopathology of skin sections collected on day 21. (1) Group A (non-treated): (a) Tumor proliferation at the skin level characterized by the presence of elongated and oval cells with strong pleomorphism $(\mathrm{HE} \times 400)$; and (b) Skin section with malignant melanoma detail with tumor necrosis $(\mathrm{HE} \times 400)$. (2) BA complex-treated group: Tumor cells with vesicular nucleus, macronucleoli, atypical mitosis; (a) $\mathrm{HE} \times 200$; and (b) $\mathrm{HE} \times 400$.

(1)

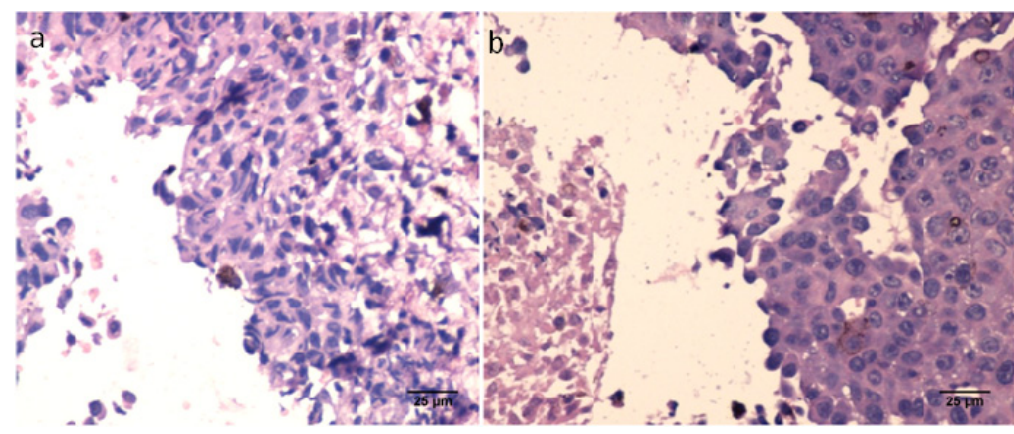


Figure 9. Cont.

(2)

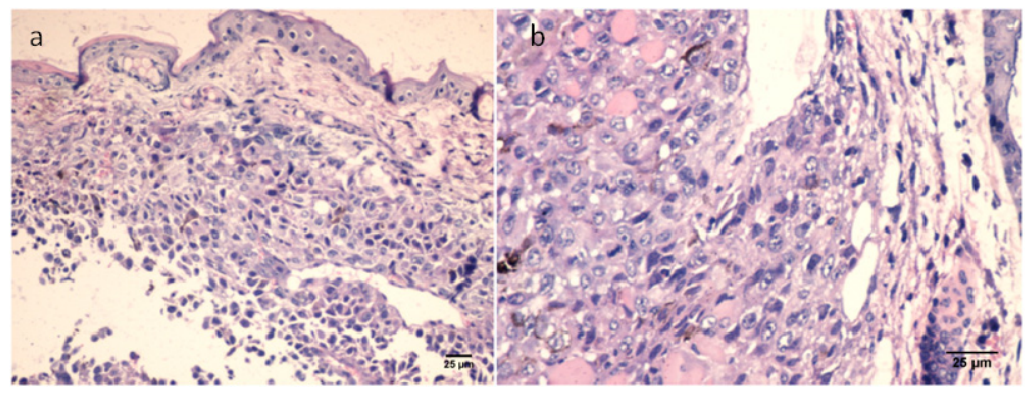

Figure 10. (a) Transepidermal water loss (TEWL); (b) Melanin index; and (c) Erythema evaluation on two experimental groups after 21 days of daily measurement. Statistic: Paired Student's $t$ tests or one-way ANOVA followed by Bonferroni's post-tests were used; $p<0.05(*), p<0.01(* *)$ and $p<0.001(* * *)$ are indicated.

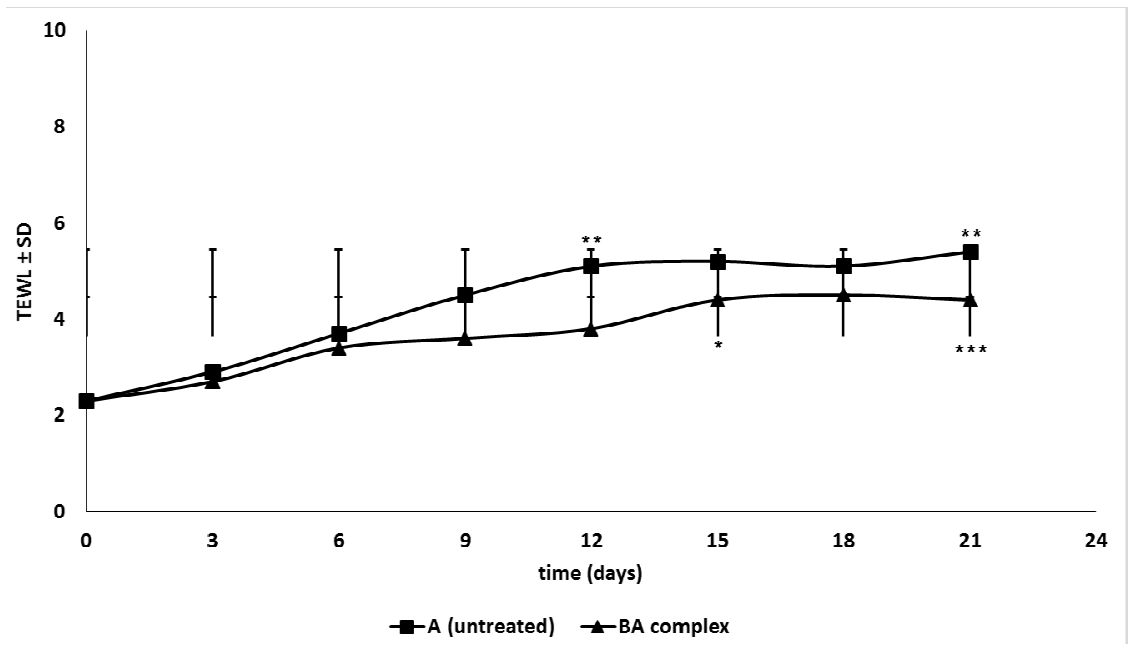

(a)

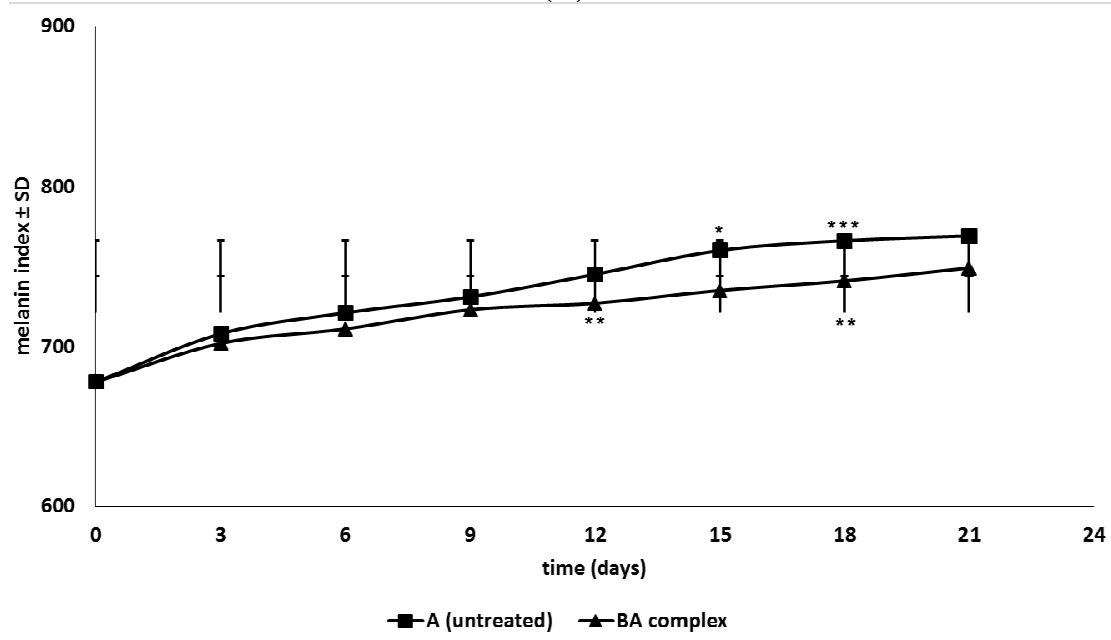

(b) 
Figure 10. Cont.

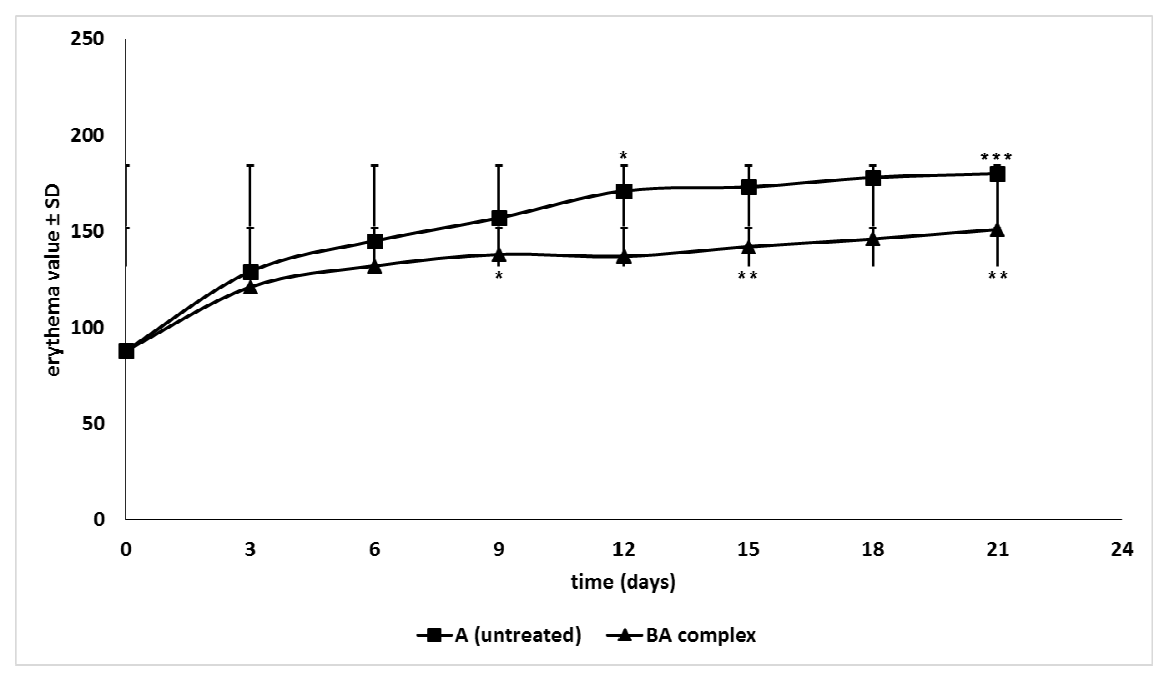

(c)

Melanin and erythema values, recorded throughout the 21-day experiment (Figure 10b,c), revealed important changes in the pathological development of the two groups of animals. Group B (treated with BA:GCDG 1:1 complex) showed smaller values for melanin and erythema levels than group A (non-treated group). Regarding TEWL (Figure 10a), a significant parameter in skin evaluation, we noticed smaller values for the treated group (group B) compared to group A.

After the inoculation of murine cells into the colored mouse strain, one can notice the increase of melanin levels [38,39]; the B164A5 cell line is one of the colored murine melanoma cell types that leads to hyper pigmentation. Tumor development can be correlated with changes in the melanin index, as observed with smaller values in the treated group. Erythema values can be correlated, in most cases, with those of melanin [38]. The reduction of the skin hemoglobin level can be related to the pathology progression but also to an intervention in the local angiogenic process at the tumor site. BA has already been proven as an active antiangiogenic agent [40], data that are corroborated with the results of the present study. Moreover, a previous study [41] reported that BA induces differentiation (into corneocytes) and cell death in normal keratinocytes. Our study showed a significant influence of BA:GCDG treatment on the skin qualitative parameters, characterized by a decrease in TEWL, melanin and erythema (Figure 10a-c), indicating impaired tumor development, which can be translated as skin protection against tumor growth. These data may correlate with other studies using BA as a topical treatment that also provided skin protection $[29,42]$.

$\mathrm{BA}$ is known as an active compound in the treatment of metastatic melanoma [43]. Additionally, it was successfully applied on experimental breast cancer and ovarian carcinoma xenografts [44,45]. In 2009, it was reported that BA suppresses tumor growth on several in vivo human xenograft models, including a melanoma model [29]. Murine melanoma also represents a target for the experimental application of BA. The murine B16/C57BL6 model rapidly metastasizes with a survival rate of approximately 30 days $[42,46]$. BA is characterized by a low water solubility that in many cases correlates with a low oral bioavailability [47] as well as the impossibility of a parenteral formulation. Increasing the solubility of several important antitumor compounds, such as paclitaxel [48], led to an improvement in tumor regression. This study investigated the possibility of the effect of BA in 
complex with a new highly soluble cyclodextrin derivative, GCDG. Substantial tumor regression was noticed in the animals of group B compared to the non-treated group A animals. The application of the water-soluble complexed BA was necessary to obtain a clear parenteral formulation; BA, being water insoluble, can only be administered orally. By increasing water solubility as a consequence of complexation, a better therapeutic outcome might likely be accomplished due to a superior distribution at the tumor level, as suggested by previous papers [49] and underscored by the decreased tumor volume observed in the treated group. BA administration in the earliest phase of the experiment was decided according to its important contribution in chemoprevention, as reported by Fulda in 2009 [29].

\section{Experimental Section}

GCDG was produced by organic synthesis at the Organic Macromolecular Chemistry Department, Saarland University, Saarbrucken, Germany and kindly given to us as a gift. Betulinic acid was purchased from Sigma Aldrich Ltd. (Taufkirchen, Germany, purity over 96\%) and used as received. All other reagents were purchased and used as received.

\subsection{Preparation of Complexes}

Cyclodextrin complexes were prepared according to the literature using the kneading method. Briefly, the physical mixture of BA and GCDG was triturated with an equal quantity of ethanol and water $(1: 1 \mathrm{v} / \mathrm{v})$. They were kneaded continuously for several minutes until most of the solvent had been evaporated; the resulted paste-type mixture was dried at room temperature $\left(25^{\circ} \mathrm{C}\right.$, normal atmospheric pressure) for $24 \mathrm{~h}$ and then at $105{ }^{\circ} \mathrm{C}$ for several hours in the oven until reaching constant weight. The final product was pulverized and sieved using a 100- $\mu \mathrm{m}$ sieve.

The binary complexes were prepared in a 1:1 BA:GCDG molar ratio.

\subsection{Scanning Electron Microscopy}

SEM pictures were captured using a JEM 100B electronic microscope (JEOL Ltd., Tokyo, Japan) functioning on scanning technique (JEM-ASID) with an accelerating voltage of $6 \mathrm{kV}$. Images were magnified by $200-10,000$ times.

\subsection{Differential Scanning Calorimetry}

DSC measurements were carried out using a Mettler Toledo STAR Thermal Analysis System, DSC 821 (Mettler Inc., Schwerzenbach, Switzerland). The gas used as carrier was argon, the heating rate was maintained at $5{ }^{\circ} \mathrm{C} / \mathrm{min}$, while the sample weight was between $2-5 \mathrm{mg}$. Experiments were conducted from 25 up to $300{ }^{\circ} \mathrm{C}$.

\subsection{X-ray Diffraction}

X-Ray-diffractograms were obtained using a Philips PW 1710 diffractometer, with $\mathrm{Cu}$ tube anode and a $K \alpha=1.54242 \AA$. The measurements were conducted using a $50 \mathrm{kV}$ tube voltage and $40 \mathrm{~mA}$ of tube current in step scan mode (step size 0.035 , counting time $1 \mathrm{~s}$ per step). 


\subsection{Isolation of Metastatic Cells}

Intraperitoneal metastases of approximately $5 \mathrm{~mm}^{3}$ were obtained from mice injected subcutaneously with melanoma tumor cells. Metastatic cells were isolated both using the explant and collagenase type IV-S from Clostridim histolyticum (Sigma Aldrich Company, Ayrshire, UK) methods. For the explant method, the metastatic samples were cut into small fragments and directly plated on cell culture-treated flasks. Tissue-isolated cells derived using the enzymatic digestion method were incubated for $15 \mathrm{~min}$ with collagenase at $37^{\circ} \mathrm{C}$, were passed through a series of phosphate buffer saline (PBS; Gibco BRL, Invitrogen, Carlsbad, CA, USA) washings, 0.70/0.40- $\mu \mathrm{m}$ strainer filtered and were replated as a single-cell suspension in adherent plastic culture plates. After isolation the cells were cultured and grown in Dulbecco's Modified Eagle Medium (DMEM; Sigma Aldrich Company) supplemented with $10 \%$ fetal calf serum (FCS; PromoCell, Heidelberg, Germany) and 2\% Penicillin/Streptomycin solution (PromoCell). The cells were kept at $37{ }^{\circ} \mathrm{C}$ in a humid atmosphere with $5 \% \mathrm{CO}_{2}$. The culture medium was discarded every third day, and the cells were passaged when they reached $80 \%-90 \%$ confluence, using $0.25 \%$ Trypsin-EDTA (ethylenediaminetetraacetic acid) solution (Sigma Aldrich Company) followed by centrifugation (10 min, 300× g). After this step, the cells were seeded in T75 culture flasks at a density of 10,000 cells $/ \mathrm{cm}^{2}$ to provide optimal growth and proliferation. Starting with the second passage, cells were partially used for further phenotypical analyses, while the subsequent experiments involved the metastatic cells expanded to passages 2-5.

All animal experiments complied with the European Convention for the Protection of Vertebrate Animals used for Experimental and Other Scientific Purposes (Directive 86/609, Strasbourg, 1986), and the experimental protocol was evaluated and approved by the "Victor Babeş" University of Medicine and Pharmacy, Timisoara, Ethics Committee and Board for Animal Experiments (IC 3/11.11.2009).

\subsection{MTT Assay}

B164A5 murine melanoma cells (5000 cells/well) (ECACC; Sigma Aldrich origin Japan stored UK) were seeded on a 96-well microplate. After $24 \mathrm{~h}$, the test compounds were added in $200 \mu \mathrm{L}$ of new medium containing Dulbecco's Modified Eagle's Medium (DMEM; Gibco BRL, Invitrogen, Carlsbad, CA, USA) supplemented with 10\% fetal calf serum (FCS; PromoCell, Heidelberg, Germany) and 1\% Penicillin/Streptomycin mixture (Pen/Strep, 10,000 IU/mL; PromoCell, Heidelberg, Germany) and incubated for $72 \mathrm{~h}$.. Melanoma cells were treated with $5 \mathrm{mM}$ EDTA and then passaged at confluence; the living cells were then evaluated by using $5 \mathrm{mg} / \mathrm{mL}$ MTT solution $(20 \mu \mathrm{L})$. After $4 \mathrm{~h}$ incubation, MTT was precipitated as blue crystals by the mitochondrial reductase from the living cells. The medium was then discarded, and the blue MTT crystals were dissolved in $100 \mu \mathrm{L}$ dimethyl sulfoxide (DMSO; Sigma-Aldrich Company, Ayrshire, UK). In the final step, the reduced MTT species were analyzed at $545 \mathrm{~nm}$ by a microplate reader; as control, the wells containing untreated cells were used. All in vitro experiments were simultaneously conducted on two microplates with at least five parallel wells. Stock solutions of the active substances were prepared using DMSO as the solvent $(10 \mathrm{mM})$, and the highest final DMSO concentration $(0.1 \%)$ of the medium did not show any significant impact on cell proliferation. 


\subsection{Cell Cycle}

All B164A5 cells (control cells, BA, BA:GCDG and GCDG-treated cells, respectively) (10 mM active compound, $72 \mathrm{~h}$ incubation time) were submitted for cell cycle analysis performed using CycleTest $^{\text {TM }}$ Plus and a DNA Reagent Kit (Becton-Dickinson, San Jose, CA, USA). Briefly, this method comprises the following steps: dissolution of cell membrane lipids, elimination of the cellular cytoskeleton and nuclear proteins, RNA digestion, and the nuclear chromatin organization followed by propidium iodide (PI) binding to the clean, isolated nuclei. All procedures were carried out according to the manufacturer protocols and started with the interaction of the cells with $250 \mu \mathrm{L}$ of Solution A (trypsin buffer) at room temperature for $10 \mathrm{~min}$. In the second phase, $200 \mu \mathrm{L}$ of Solution B (trypsin inhibitor and RNase buffer) was added, followed by a 10-min rest at room temperature; finally, $200 \mu \mathrm{L}$ of cold $\left(2-8{ }^{\circ} \mathrm{C}\right)$ Solution $\mathrm{C}$ (propidium iodide stain solution) was added, gently mixed and incubated for $10 \mathrm{~min}$ in the refrigerator protected from light.

Annexin V/PI assay data acquisition/cell cycle were performed on a four-color capable FACSCalibur (Becton-Dickinson) flow cytometer; data analysis was carried out using CellQuest Pro software (Becton-Dickinson).

\subsection{Annexin V/PI Assay}

All B164A5 cells (control cells, BA, BA:GCDG and GCDG-treated cells, respectively) (10 mM active compound, $72 \mathrm{~h}$ incubation time) were used in the apoptosis assay. Annexin V-FITC (Miltenyi Biotec, Gladbach, Germany) and Propidium Iodide Staining Solution (BD Biosciences, San Jose, CA, USA) were used in cell death flow cytometric analysis (apoptosis) according to the manufacturers' protocols. Briefly, $10^{6}$ cells were washed in Annexin V Binding Buffer (BD Pharmigen, San Jose, CA, USA) and centrifuged at $300 \times \mathrm{g}$. Afterwards, the cells were resuspended using the same solution and incubated for $15 \mathrm{~min}$ with $10 \mu \mathrm{L}$ of Annexin V-FITC, protected from light. The cells were washed with $1 \mathrm{~mL}$ of specific binding buffer and then centrifuged, and the resulted cell pellet was resuspended in $500 \mu \mathrm{L}$ of binding buffer; $1 \mu \mathrm{g} / \mathrm{mL}$ PI solution was added, followed by flow cytometrical analysis.

\subsection{Statistical Analysis}

All experiments were carried out in triplicate to provide accurate statistical analysis. The results were statistically evaluated and expressed as the mean \pm standard error. The differences between the means were analyzed using one way ANOVA followed by Bonferroni's post-test; $p<0.05$ was considered statistically significant.

\subsection{Ethics Statement}

All experimental procedures were evaluated and approved by the Ethical Committee of the Victor Babeş University of Medicine and Pharmacy, Timisoara, Romania. The experimental protocol was performed under the NIAH-National Institute of Animal Health rules; throughout the experiment, animals were kept under standard recommended conditions: $12 \mathrm{~h}$ light-dark cycle, ad libitum water and 
food, $24{ }^{\circ} \mathrm{C}$ temperature, and above $55 \%$ humidity). At the end of the experiment, the procedure for animals'sacrifice was cervical dislocation.

\subsection{Animal Studies}

Animal studies were conducted on 8-week-old C57BL/6J female mice (22-25 g average weight). The mice were purchased from Charles River (Sulzfeld, Germany). The experiment involved 20 animals equally divided into two groups as follows: group A, inoculated with B164A5 cells; group B, inoculated with B164A5 cells and then treated with BA complex in saline solution. We decided to use the group of mice that received no treatment as a control because of the results we obtained in one of our previous studies [46], where we analyzed the effect of GCDG both in vitro and in vivo, and no influence regarding a pharmacological effect or toxicity of this compound was detected.

B164A5 (ECACC and Sigma Aldrich, origin Japan stored UK) cells were processed as described in the MTT assay protocol. On day 0 of the experiment, the animals from the two groups, A and B, were subcutaneously inoculated, into the hair-depilated lateral abdomen, with $0.1 \mathrm{~mL}$ of $1 \times 10^{5}$ cells/mouse [38]. The mice were monitored daily throughout the experiment so that the development of tumors or other significant changes could be noticed. Tumors became clear and visible on day 9 after inoculation. Tumor growth $(\mathrm{mm})$ was measured daily using a caliper, and tumor volume was estimated using the following formula: length $\times$ width $^{2} / 2$ [50]. The administration of the BA complex to animals from group B started on the first day after the murine melanoma cell inoculation and was performed daily (100 mg/kg, intraperitoneally) until the final day of the experiment. Because BA is water-insoluble, it could not be administered as an aqueous solution. The experiment lasted 21 days from the inoculation; the survival rate was $100 \%$ for both groups. Tumors were collected, measured, weighed and analyzed by classical histological techniques. The results are expressed as the mean \pm SD Statistical analysis were performed for tumor volume and weight using one-way ANOVA followed by Bonferroni's post-test or paired Student's $t$ tests, depending on the case; $p<0.05$ was considered significant.

\subsection{Non-Invasive Skin Measurements}

For all non-invasive measurements carried out on the mouse skin, a Multiprobe Adapter System (MPA5) from Courage-Khazaka (Cologne, Germany) was used; the melanin and erythema measurements were performed using a Mexameter ${ }^{\circledR}$ MX 18 (Courage-Khazaka) that offers quantitative information regarding the melanin and erythema (hemoglobin) level subjected to modifications following tumor development with or without treatment. The device emits light over 3 wavelengths (568, 660 and $880 \mathrm{~nm}$ ) and measures the remitted light over a 5-mm diameter. The erythema and melanin indices are determined as follows:

$$
\begin{gathered}
M x=\frac{500}{\log 5} \log \frac{\text { Infrared }}{\text { Red }}+\log 5 \\
E x=\frac{500}{\log 5} \log \frac{\text { Red }}{\text { Green }}+\log 5
\end{gathered}
$$

where $M x=$ melanin index; $E x=$ erythema index; and infrared/red/green = infrared/red/green remittance. 
These indices are relative values, and the maximum ratio between each color is 1:5. The values are within the range of $0-1000$, with a higher value representing an increased melanin or erythema level, while a value of 500 represents a remittance ratio of 1:1. All measurements were carried out in four skin regions located near the tumor, and mean and standard deviation were calculated [51]. Statistical tests were used to determine the significant differences between the two experimental groups. The amount of melanin and erythema was measured at baseline (day 0 ) and then every other day until day 21 of the experiment. The measurement area was $5 \mathrm{~mm}$ in diameter. At the end of experiment, mice were sacrificed, and the skin was collected and histologically analyzed.

\subsection{Histology}

For the histological analysis, tissue samples (skin) were fixed in a $10 \%$ formalin solution and then embedded in paraffin and cut at four microns. Finally, after the removal of paraffin, the samples were stained with hematoxylin-eosin (HE) and microscopically analyzed.

\section{Conclusions}

$\mathrm{BA}$ is an active agent for the treatment of murine metastatic melanoma. It has a significant negative impact on tumor growth, leading to a reduced pathology and an increased survival time. Moreover, $\mathrm{BA}$ is a skin protective agent and, consequently, an important candidate for in vivo melanoma treatment.

\section{Acknowledgments}

The authors wish to thank Gerhard Wenz and Hai Ming Wang from the Organic Macromolecular Chemistry Department, Saarland University, Saarbrucken, Germany for kindly providing the cyclodextrin (GCDG) that was used in all experiments in the present paper.

This work was supported by UEFISCDI, PN II — Capacităţi, CT-163/22.04.2013, Module III—bilateral projects Romania-Hungary; contract 674/22.04.2013 and 665/22.04.2013. This work was also supported by a grant from the Victor Babeş University of Medicine and Pharmacy, Timisoara (Grant PIII-C1-CFI-2014/2015-03 to C.S.).

\section{Author Contributions}

CS designed the entire study, participated in the physico-chemical tests and conceived the draft; $\mathrm{CD}$, IZ, FB4 contributed to the in vitro study and interpreted the results; GS-B, DC, SC and CAD participated to the animal study and writing the article; FB1 and RA participated in the physico-chemical tests; SA performed histological analysis; TO and PM participated to the animal study and contributed to the final form of the manuscript.

\section{Conflicts of Interest}

The authors declare no conflict of interest. 


\section{References}

1. Pisha, E.; Chai, H.; Lee, I.-S.; Chagwedera, T.E.; Farnsworth, N.R.; Cordell, G.A.; Beecher, C.W.W.; Fong, H.H.S.; Douglas Kinghorn, A.; Brown, D.M.; et al. Discovery of betulinic acid as a selective inhibitor of human melanoma that functions by induction of apoptosis. Nat. Med. 1995, 1, 1046-1051.

2. Mullauer, F.B.; Kessler, J.H.; Medema, J.P. Betulinic acid, a natural compound with potent anticancer effects. Anticancer Drugs 2010, 21, 215-227.

3. Şoica, C.; Peev, C.; Dehelean, C.; Aluas, M.; Zupko, I.; Kasa, P.; Alexa, E. Physico-chemical comparison study of betulinic acid, betulin and birch bark extract and in vitro investigation of their cytotoxic effects towards skin epidermoid carcinoma (A431), breast carcinoma (MCF7) and cervix adenocarcinoma (HeLa) cell-lines. Nat. Prod. Res. 2012, 26, 968-974.

4. Zuco, V.; Supino, R.; Righetti, S.C.; Cleris, L.; Marchesi, E.; Gambacorti-Passerini, C.; Formelli, F. Selective cytotoxicity of betulinic acid on tumor cell lines, but not on normal cells. Cancer Lett. 2002, 175, 17-25.

5. Drag, M.; Surowiak, P.; Drag-Zalesinska, M.; Dietel, M.; Lage, H.; Oleksyszyn, J. Comparision of the cytotoxic effects of birch bark extract, betulin and betulinic acid towards human gastric carcinoma and pancreatic carcinoma drug-sensitive and drug-resistant cell lines. Molecules 2009, 14, 1639-1651.

6. Rieber, M.; Strasberg Rieber, M. Induction of p53 without increase in p21WAF1 in betulinic acid-mediated cell death is preferential for human metastatic melanoma. DNA Cell Biol. 1998, 17, 399-406.

7. Sawada, N.; Kataoka, K.; Kondo, K.; Arimochi, H.; Fujino, H.; Takahashi, Y.; Miyoshi, T.; Kuwahara, T.; Monden, Y.; Ohnishi, Y. Betulinic acid augments the inhibitory effects of vincristine on growth and lung metastasis of B16F10 melanoma cells in mice. Br. J. Cancer 2004, 90, 1672-1678.

8. Cichewicz, R.H.; Kouzi, S.A. Chemistry, biological activity, and chemotherapeutic potential of betulinic acid for the prevention and treatment of cancer and HIV infection. Med. Res. Rev. 2004, 24, 90-114.

9. Şoica, C.M.; Peev, C.I.; Ciurlea, S.; Ambrus, R.; Dehelean, C. Physico-chemical and toxicological evaluations of betulin and betulinic acid interactions with hydrophilic cyclodextrins. Farmacia 2010, 58, 611-619.

10. Dehelean, C.A.; Soica, C.; Peev, C.; Ciurlea, S.; Feflea, S.; Kasa, P., Jr. A pharmaco-toxicological evaluation for betulinic acid mixed with hydroxipropilgamma cyclodextrin on in vitro and in vivo models. Farmacia 2011, 59, 51-59.

11. Dehelean, C.; Şoica, C.; Peev, C.; Gruia, A.T.; Şeclaman, E. Physico-chemical and molecular analysis of antitumoral pentacyclic triterpenes in complexation with gamma-cyclodextrin. Rev. Chim. 2008, 59, 887-890.

12. Şoica, C.; Dehelean, C.; Peev, C.; Coneac, G.; Gruia, A.T. Complexation with hydroxipropil $\gamma$ cyclodextrin of some pentacyclic triterpenes. Characterisation of their binary products. Farmacia 2008, 56, 182-190. 
13. Iyer, A.K.; He, J.; Amiji, M.M. Image-guided nanosystems for targeted delivery in cancer therapy. Curr. Med. Chem. 2012, 19, 3230-3240.

14. Wang, H.M.; Soica, C.; Wenz, G. A comparison investigation on the solubilization of betulin and betulinic acid in cyclodextrin derivatives. Nat. Prod. Commun. 2012, 7, 289-291.

15. Yamamura, S.; Momose, Y. Quantitative analysis of crystalline pharmaceuticals in powders and tablets by a pattern-fitting procedure using X-ray powder diffraction data. Int. J. Pharm. 2001, 212, 203-212.

16. Dehelean, C.A.; Feflea, S.; Molnár, J.; Zupko, I.; Soica, C. Betulin as an antitumor agent tested in vitro on A431, HeLa and MCF7, and as an angiogenic inhibitor in vivo in the CAM assay. Nat. Prod. Commun. 2012, 7, 981-985.

17. Li, Y.; He, K.; Huang, Y.; Zheng, D.; Gao, C.; Cui, L.; Jin Y.H. Betulin induces mitochondrial cytochrome $c$ release associated apoptosis in human cancer cells. Mol. Carcinog. 2010, 49, 630-640.

18. Rzeski, W.; Stepulak, A.; Szymański, M.; Juszczak, M.; Grabarska, A.; Sifringer, M.; Kaczor, J.; Kandefer-Szerszeń, M. Betulin elicits anti-cancer effects in tumour primary cultures and cell lines in vitro. Basic Clin. Pharmacol. Toxicol. 2009, 105, 425-432.

19. Eiznhamer, D.A.; Xu, Z.-Q. Betulinic acid: A promising anticancer candidate. IDrugs 2004, 7, 359-373.

20. Fulda, S.; Debatin, K.-M. Sensitization for anticancer drug-induced apoptosis by betulinic acid. Neoplasia 2005, 7, 162-170.

21. Sami, A.; Taru, M.; Salme, K.; Jari, Y-K. Pharmacological properties of the ubiquitous natural product betulin. Eur. J. Pharm. Sci. 2006, 29, 1-13.

22. Mendonca, E.A.; Lira, M.C.; Rabello, M.M.; Cavalcanti, I.M.; Galdino, S.L.; Pitta, I.R.; Lima Mdo, C.; Pitta, M.G.; Hernandes, M.Z.; Santos-Magalhães, N.S. Enhanced antiproliferative activity of the new anticancer candidate LPSF/AC04 in cyclodextrin inclusion complexes encapsulated into liposomes. AAPS PharmSciTech 2012, 13, 1355-1366.

23. Pourgholami, M.H.; Wangoo, K.T.; Morris, D.L. Albendazole-cyclodextrin complex: Enhanced cytotoxicity in ovarian cancer cells. Anticancer Res. 2008, 28, 2775-2779.

24. Liu, Y.; Chen, G.S.; Chen, Y.; Cao, D.X.; Ge, Z.Q.; Yuan, Y.J. Inclusion complexes of paclitaxel and oligo(ethylenediamino) bridged bis(b-cyclodextrin)s: Solubilization and antitumor activity. Bioorg. Med. Chem. 2004, 12, 5767-5775.

25. Rieber, M.; Rieber Strasberg, M. Signalling responses linked to betulinic acid-induced apoptosis are antagonized by MEK inhibitor U0126 in adherent or 3D spheroid melanoma irrespective of p53 status. Int. J. Cancer 2006, 118, 1135-1143.

26. Cheng, Y.Q.; Chen, Y.; Wu, Q.L.; Fang, J.; Yang, L.J. Effect of betulinic acid on inducing apoptosis of human multiple myeloma cell line RPMI-8226. Zhongguo Shi Yan Xue Ye Xue Za Zhi 2009, 17, 1224-1229.

27. Chen, Z.; Wu, Q.; Chen, Y.; He, J. Effects of betulinic acid on proliferation and apoptosis in Jurkat cells and its in vitro mechanism. J. Hua Zhong Univ. Sci. Technol. Med. Sci. 2008, 28, 634-638. 
28. Vadivelu, R.K.; Yeap, S.K.; Ali, A.M.; Hamid, M.; Alitheen, N.B. Betulinic acid inhibits growth of cultured vascular smooth muscle cells arrest and apoptosis. Evid-Based Complement. Altern. Med. 2012, 2012, 251362.

29. Fulda, S.; Kroemer, G. Targeting mitochondrial apoptosis by betulinic acid in human cancers. Drug Discov. Today 2009, 14, 885-890.

30. Santos, R.C.; Salvador, J.A.R.; Cortés, R.; Pachón, G.; Marín, S.; Cascante, M. New betulinic acid derivatives induce potent and selective antiproliferative activity through cell cycle arrest at the $\mathrm{S}$ phase and caspase dependent apoptosis in human cancer cells. Biochimie 2011, 93, 1065-1075.

31. Zaritskaya, L.; Shurin, M.R.; Sayers, T.J.; Malyguine, A.M. New flow cytometric assays for monitoring cell-mediated cytotoxicity. Expert Rev. Vaccines 2010, 9, 601-616.

32. Mullauer, F.B.; Kessler, J.H.; Medema, J.P. Betulinic acid induces cytochrome $c$ release and apoptosis in a Bax/Bak-independent, permeability transition pore dependent fashion. Apoptosis 2009, 14, 191-202.

33. Fulda, S.; Debatin, K.M. Betulinic acid induces apoptosis through a direct effect on mitochondria in neuroectodermal tumors. Med. Pediatr. Oncol. 2000, 35, 616-618.

34. Liu, W-K.; Ho, J.C.K.; Cheung, F.W.K.; Liu, B.P.L.; Ye, W-C.; Che, C-T. Apoptotic activity of betulinic acid derivatives on murine melanoma B16 cell line. Eur. J. Pharmacol. 2004, 498, 71-78.

35. Serradell, M.; Díaz-Ricart, M.; Cases, A.; Petriz, J.; Ordinas, A.; Escolar, G. Uraemic medium accelerates proliferation but does not induce apoptosis of endothelial cells in culture. Nephrol. Dial. Transplant. 2003, 18, 1079-1085.

36. Rubio, N.; Torres, C. Interferon- $\gamma$ induces proliferation but not apoptosis in murine astrocytes through the differential expression of the myc proto-oncogene family. Mol. Brain Res. 1999, 71, 104-110.

37. Harmand, P.O.; Duval, R.; Delage, C.; Simon, A. Ursolic acid induces apoptosis through mitochondrial intrinsic pathway and caspase-3 activation in M4Beu melanoma cells. Int. J. Cancer 2005, 114, 1-11.

38. Danciu, C.; Borcan, F.; Bojin, F.; Zupko, I.; Dehelean, C. Effect of the isoflavone genistein on tumor size, metastasis potential and melanization in a B16 mouse model of murine melanoma. Nat. Prod. Commun. 2013, 8, 343-346.

39. Cinta Pinzaru, S.; Falamas, A.; Dehelean, C.A. Molecular conformation changes along the malignancy revealed by optical nanosensors. J. Cell. Mol. Med. 2013, 17, 277-286.

40. Dehelean, C.A.; Feflea, S.; Ganta, S.; Amiji, M.M. Anti-angiogenic effects of betulinic acid administered in nanoemulsion formulation using chorioallantoic membrane assay. J. Biomed. Nanotechnol. 2011, 7, 317-324.

41. Galgon, T.; Wohlrab, W.; Dräger, B. Betulinic acid induces apoptosis in skin cancer cells and differentiation in normal human keratinocytes. Exp. Dermatol. 2005, 14, 736-743.

42. Ciurlea, S.A.; Dehelean, C.A.; Ionescu, D.; Berko, S.; Csanyi, E.; Hadaruga, D.I.; Ganta, S.; Amiji, M.M. A comparative study regarding melanoma activity of betulinic acid on topical ointment vs. systemic nanoemulsion delivery systems. J. Agroaliment. Process. Technol. 2010, $16,420-426$. 
43. Fulda, S. Betulinic acid for cancer treatment and prevention. Int. J. Mol. Sci. 2008, 9, 1096-1107.

44. Yogeeswari, P.; Sriram, D. Betulinic acid and its derivatives: A review on their biological properties. Curr. Med. Chem. 2005, 12, 657-666.

45. Mertens-Talcott, S.U.; Noratto, G.D.; Li, X.; Angel-Morales, G.; Bertoldi, M.C.; Safe, S. Betulinic acid decreases ER-negative breast cancer cell growth in vitro and in vivo: Role of $\mathrm{Sp}$ transcription factors and microRNA-27a: ZBTB10. Mol. Carcinog. 2013, 52, 591-602.

46. Şoica, C.; Dehelean, C.; Danciu, C.; Wang, H.M.; Wenz, G.; Ambrus, R.; Bojin, F.; Anghel, M. Betulin complex in $\gamma$-cyclodextrin derivatives: Properties and antineoplasic activities in vitro and in vivo tumor models. Int. J. Mol. Sci. 2012, 13, 14992-15011.

47. Xu, W.; Ling, P.; Zhang, T. Polymeric micelles, a promising drug delivery system to enhance bioavailability of poorly water-soluble drugs. J. Drug Deliv. 2013, 2013, 340315.

48. Lee, S.C.; Huh, K.M.; Lee, J.; Cho, Y.W.; Galinsky, R.E.; Park, K. Hydrotropic polymeric micelles for enhanced paclitaxel solubility: In vitro and in vivo characterization. Biomacromolecules 2007, 8, 202-208.

49. Awasthi, N.; Zhang, C.; Schwarz, A.M.; Hinz, S.; Wang, C.; Williams, N.S.; Schwarz, M.A.; Schwarz, R.E. Comparative benefits of Nab-paclitaxel over gemcitabine or polysorbate-based docetaxel in experimental pancreatic cancer. Carcinogenesis 2013, 34, 2361-2369.

50. Giavazzi, R.; Campbell, D.E.; Jessup, J.M.; Cleary, K.; Fidler, I.J. Metastatic behavior of tumor cells isolated from primary and metastatic human colorectal carcinomas implanted into different sites in nude mice. Cancer Res. 1986, 46, 1928-1933.

51. Hoshino, T.; Matsuda, M.; Yamashita, Y.; Takehara, M.; Fukuya, M.; Mineda, K.; Maji, D.; Ihn, H.; Adachi, H.; Sobue, G.; et al. Suppression of melanin production by expression of hsp70. J. Biol. Chem. 2010, 285, 13254-13263.

(C) 2014 by the authors; licensee MDPI, Basel, Switzerland. This article is an open access article distributed under the terms and conditions of the Creative Commons Attribution license (http://creativecommons.org/licenses/by/3.0/). 